\title{
Analysis on the Reform Method of Photography Teaching in Colleges and Universities under the New Media Technology
}

\author{
Liang Bin \\ School of Literature, Xi'an University, Xi'an, Shaanxi, China, 710065
}

Keywords: New Media Technology; Photography Teaching; Current Problem; Teaching Reform

Abstract: New media technology has been emerged under the dual function of economic improvement and scientific and technological development. It is unique in the field of media, and has also brought advantageous effect and positive effect which cannot be underestimated for other industries. It has become an inevitable trend to integrate modern equipment into college teaching at the present stage, and new media technology has great convenience and efficiency for different specialties in colleges and universities, including teaching of photography major. In view of this, the reform method of photography teaching in colleges and universities under the new media technology is taken as the core argument in this paper to explore the crux of its problems and try to propose corresponding solutions by analyzing the present situation and problems of photography teaching in colleges and universities mainly from influences and functions of new media technology on photography teaching in colleges and universities as break through point of the thesis.

\section{Introduction}

The content of education should keep pace with the times, and the teaching methods should keep in step with the times. The traditional educational ideas and methods in our country have some drawbacks in terms of teaching approaches and teaching results. The emergence and development of new media technology has undoubtedly provided certain help for the teaching of various specialties, which breaks the old teaching thinking and the way of communication between teachers and students, and enables the teaching to be more interesting and flexible. By using image, audio, video and other auxiliary means, it greatly promotes the students' absorption and digestion of knowledge points, thus improving the classroom efficiency. In addition, the new media technology enables teaching to enjoy certain advantages in terms of resources, making the textbook content more rich and diverse, and the students' knowledge can be expanded and improved. In the current photography teaching in colleges and universities, the new media technology has been valued and applied by many colleges and universities, which enables photography teaching to jump out of the boring theoretical framework of the classroom in practice so as to achieve certain results through a richer, and more interesting teaching feedback path. 


\section{Influences and functions of new media technology on photography teaching in colleges and universities}

The emergence and development of photography technology has always been developed accompanied by the development of the times, which has a more prominent flavor of the times compared with other art categories. In particular, it is closely related to the development of computer technology, promoting the diversification and modernization of this technology. At present, most colleges and universities have applied the new media technology to photography teaching, while this technology has a great impact on photography teaching. It will be discussed later on from three different perspectives.

\subsection{Explanation from the perspective of communication between teachers and students}

In the teaching process, whether teachers and students can have good and effective communication is the key to achieve certain achievements in teaching. However, due to the misunderstanding between people, there are some differences in the communication between teachers and students. In particular, it is easier for the traditional blackboard-writing teaching method to make this communication more passive and difficult. Therefore, the application of new media technology to photography teaching can greatly promote communication between teachers and students. Since the knowledge covered by the new media technology in teaching is based on a more active and richer system, which promotes students to absorb theoretical knowledge actively from the visual, auditory and other levels, and helps students to receive, think, and understand classroom difficulties and abstractions in all respects coupled with images, videos, music and other auxiliary means on the basis of theory.

\subsection{Explanation from the perspective of technology level}

In addition to having basic photography theory, aesthetic knowledge and artistic literacy, the photographer's photography technology is also particularly critical. The working principle and design method of the camera are developed closely followed by the needs of the times and the development of digital technology, and its specialty is reflected in the unusual processing of ordinary image. Therefore, teachers should be able to transmit the new technology and information to the students in the teaching timely, integrate the relevant contents and processing methods of digital photography into the teaching activities properly, and help students to keep pace with the times in the process of learning at the technical level.

\subsection{Explanation from the perspective of teaching effect}

As the new media technology expands the teaching resources, teachers can not only transmit rich professional knowledge in the class, but also the students can use this technology to consult knowledge by themselves after the class, and take the initiative to obtain more professional resources. New media technology conforms to the high efficiency, low cost, intuitive and convenient psychological needs of people in this pluralistic era, which is the optimal path to achieve the goal of photography teaching. It uses multiple ways to enable students to have stronger experience feeling and participation sense, which greatly promotes the effectiveness of teaching.

\section{Current situation and problems of photography teaching in colleges and universities}

The photography major is started relatively late in our higher education. As a relatively new 
discipline, its development in recent years is also quite rapid, which benefits from the catalysis of science and technology and digital technology. However, due to the differences in the nature of colleges and universities, the teaching development of photography major also has the unbalanced development. This is mainly reflected in the following three points:

\subsection{Teaching objectives are not clear enough}

Traditional photography has the professional nature of recording and documentary. From a macroscopic viewpoint, this nature in the contemporary era has been difficult to bear the identity of cultural carrier. Under the promotion of the overall artistic concept, the integration of cross-discipline and cross-cutting is the main channel to promote the progress and development of each professional field. Contemporary photographers have more individuation and subjectivity in terms of technology and concept control. In order to flexibly use photography technology to achieve a variety of purposes, such as recording, communication and argumentation, it is necessary to cultivate a comprehensive and versatile photographic talent. As photography professionals are often controversial in the level of technology, ideas and employment, the teaching objectives of photography in many colleges and universities are not clear enough, and even the photography teachers do not realize the true role of photography in modern society beyond the employment of photography, and fail to convey to students the value of their humanistic level, and lack of expression at the cultural level. As a consequence, the creativity of students in the process of learning photography is severely restricted, and the promotion and development of photography teaching is slowed down.

\subsection{Shortage of teaching methods}

From the background of new media technology, although the mean of photography teaching in colleges and universities has changed, it is still limited, and there are many deficiencies in teaching activities, which is mainly reflected in three aspects: the single teaching method, the lagging of textbooks theory, and the shortage of teaching equipment. The lack of teaching means is the basic reason why the teaching process is boring and the teaching results are difficult to improve, which greatly affects the students' initiative in the classroom.

\subsection{Deficiency of faculty}

As photography has a certain specialty, it is necessary for photographers to master the skills in both technical and artistic aspects. However, since there are not many outstanding talents in this major, in addition, many colleges and universities have not made efforts to introduce talents so that there is lack of good teachers in photography teaching, thus making it difficult for students to obtain the best teaching experience and the most comprehensive and systematic professional knowledge in the process of learning.

\section{Countermeasures of teaching reform of photography course in colleges and universities under the new media technology}

The countermeasures are put forward below in a targeted manner through the analysis of current situation and problems of photography course teaching in colleges and universities. 


\subsection{Define teaching concept}

Photography education in colleges and universities is the main way to promote the development of photography major in China. The teaching concept of photography under the new media technology should be pluralistic and not chaotic. Defining the concept of photography teaching can effectively improve its teaching results and play a vital role in the development direction of photography culture. Therefore, when considering the purpose of photography, the educator should start it from a comprehensive perspective and not be confined to a narrow range, get rid of the transmission of knowledge about photography techniques, photography methods, photographic history and photography theory. Furthermore, students should be encouraged to control the visual psychology and image perception, and the purpose and value of photography teaching can be better demonstrated through the guidance and training of this ability.

\subsection{Enrich teaching methods}

In order to enrich the method of photography teaching, we must first break the teaching methods, which do not adapt to the new situation from the inherent teaching activities, and introduce the new teaching means and teaching ideas into them by using the new media technology. For example, teachers can make great efforts to develop the emerging photography knowledge in the new media era on the basis of inherent teaching, and make use of various methods such as classroom discussion, multimedia technology, professional practice, and academic exchanges to improve students' creative enthusiasm and initiative, and provide an active learning atmosphere for photography teaching. Rich teaching methods are helpful for students to master theoretical knowledge and professional technology, and to improve their ability of expression and practice.

\subsection{Increase investment in hardware}

Photography itself requires a high level of hardware investment. At present, the development of photographic equipment is developed very quickly, and its update speed is basically half of a year as a cycle. In the past, due to the influence of funds and concepts, the hardware investment of photography courses in colleges and universities has been barely satisfactory. We should try our best to construct the hardware of photography course and set up humanized equipment and photography field to allow the students to borrow the corresponding equipment according to their needs. For outdated photographic equipment, the school can organize the students to purchase it in the form of auctions, continuing the virtuous cycle.

\subsection{Expand faculty}

On one hand, the expansion of faculty lies in the improvement of teachers' ability, on the other hand, it also lies in the attention paid by colleges and universities to the introduction of talents. In order to improve their own ability, teachers should not only pay attention to the improvement of their professional quality and professional level, but also concentrate on the ability of transmitting knowledge and teaching effectively. If the teachers only have first-class photography and avant-garde photography, but do not know how to teach students, it will greatly reduce the efficiency and results of teaching. Next, when recruiting talents, colleges and universities should fully consider various factors, select talents with both professional ability and teaching ability, increase the faculty, work out a feasible program according to the current situation of photography teaching, and further develop the teachers' professional literacy through regular professional training for teachers, or organization of related lectures and exchange activity with other institutions 
and professions so as to achieve the purpose of expanding faulty.

\subsection{Multi-organizational browsing exchange and other academic activities}

According to the actual conditions of the school, we should organize as many academic activities such as browsing and exchanging as possible to enable the students to participate in the creation of the works as much as possible, creating a good display space for the students. Academic exchange should not be restricted to the major and the discipline, and even some interdisciplinary academic exchange activities can be organized (if condition allowed) to strive to make students summarize and improve in the activities, and fully mobilize the creation enthusiasm and enthusiasm of students.

\section{Conclusion}

With the promotion of new media technology, although the photography teaching has changed in all aspects, it still needs to be improved as a whole, especially in terms of teaching objectives, teaching methods, teaching resources and so on. Therefore, teachers in universities and colleges shall fully grasp the teaching content in the daily teaching activities, make proper adjustment to the curriculum, and combine knowledge with practice organically. In teaching activities, teachers should always follow the teaching concept of "people-oriented", and take the advantages of new media technology to cultivate students' enthusiasm and initiative in photography courses. In addition, colleges and universities should also attach great importance to the level of teachers and teaching equipment, and strive to create an active teaching atmosphere for photography teaching in colleges and universities in order to train more photographic talents for our country.

\section{References}

[1] Yu Fangting. Analysis of the Teaching of Foundation Courses of Film and Video Directors under the New Media Environment[J].Science \& Technology Economy Market, 2016(05).

[2] Jiao Jian. New Media Art Photography Course [M]. Hangzhou: China Academy of Art Press, 2007.

[3] Wang Chong. Research on Practical Teaching in Photography [J]. Youth Literator, 2009 (11).

[4] Yang Jian. Multimedia Transformation of College News Photography Teaching in the Age of Media Convergence [J]. Journal of Communication University of Zhejiang, 2013, 05: 100-104.

[5] Zhou Hu. Exploring the reform of news photography education in the new media era [J]. News Window, 2014, 06: 56-57.

[6] Yang Jian. The change of news photography teaching in the era of media integration [J]. Young reporter, 2013, 32: 98-99.

[7] Song Xiaona; Role of Basic Photography and Research on the Teaching Reform in Educational Technology Major [D]. Shandong Normal University. 2008.

[8] Li Gang; Zhu Lin; Research on Practical Teaching of Photography Course [J]; Journal of Fuyang Teachers College (Social Science Edition).2009.03.

[9] Liao Gang; Exploration of Elementary Course of Photography Course in Colleges and Universities [J]; Liaoning Education Research. 2010.07. 